\title{
La importancia de la historia para el desarrollo de la Terapia Ocupacional ${ }^{1}$
}

\author{
The importance of history for the development \\ of Occupational Therapy
}

Liliana Tenorio Rebolledo ${ }^{2}$

"Entre urdimbre y trama se teje la vida.

Del nopal y el agua el alma se pinta.

Siguiendo el compás del hilo en mis manos mira nada más hasta donde he venido a parar"

Marta Gómez, 2013, de la canción Llévame en tus Alas

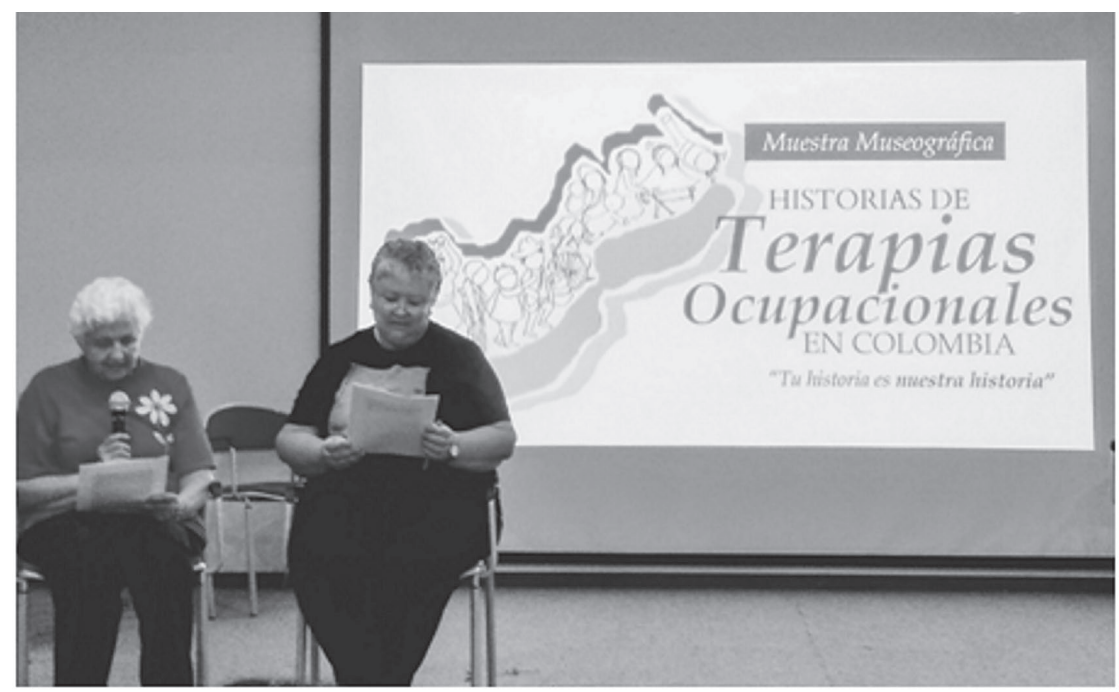

Carmen Helena Vergara y Liliana Tenorio, durante la lectura y discusión de este texto el viernes 3 de marzo de 2017 en la Universidad del Valle.

Foto: Cortesía Mauricio Varela.

\footnotetext{
${ }^{1}$ Este texto fue presentado el 3 de marzo de 2017 en el evento de inauguración de la Muestra Museográfica Historias de Terapias Ocupacionales en Colombia en la ciudad de Cali, llevado a cabo en la Universidad del Valle en el marco de la celebración de los treinta años de creación del programa de Terapia Ocupacional en esa institución. En ese escenario, fue la base de una conversación entre la autora y su colega y amiga, Carmen Helena Vergara; la fotografía registra ese momento.

${ }^{2}$ Terapeuta Ocupacional. Magíster en Economía. Universidad del Valle. Cali, Colombia. lilianatenorio@gmail. com
} 
La Historia de la Terapia Ocupacional vista desde hoy hacia atrás, desde mi lugar más bien de frontera, la veo con un pensamiento nómada que se mueve en un hilvanar de balbuceos éticos, que se ubica en períodos y que no puede quedarse atrapada en conceptos fijos y definitivos. La reflexión se basa en una identificación de sucesos cotidianos que, aunque parecieran insignificantes y anecdóticos, ligados a personas con rostros y a sus interacciones, hoy consolidan un cuerpo del conocimiento y pertenecen al desarrollo de la Terapia Ocupacional.

El devenir de la Terapia Ocupacional está ligado con su campo de acción. Ese campo de acción se puede comparar con una pieza de tejido en donde se aprecia el entretejido de los conocimientos, las experiencias, las acciones y las interpretaciones de las personas que se desempeñan en esa profesión. Al interior del campo han pasado muchas hebras que se mueven unas con otras y que han ido estructurando la pieza. Para poder Ilamarla pieza de tejido debe estar conformada por límites precisos que definen el tamaño, la forma y la cualidad de sus materiales, es lo que conocemos en su referente académico como frontera de la ciencia. La delimitación de esa frontera del conocimiento identifica unas prácticas y unos saberes propios de una disciplina, más allá de ella empieza la ignorancia. El movimiento de los límites entre los saberes, las prácticas y la ignorancia sobre ciertos aspectos es lo que llamamos el devenir de una disciplina; las características de esa pieza de tejido, como el movimiento de las hebras al interior, la trama de saberes y la urdimbre de la es- tructura primigenia, son las que le han dado con el tiempo su consolidación. Como en toda pieza de tejido, hay elementos sueltos e incluso algunos que hoy ya no están presentes; por ejemplo, el conocimiento de los oficios y de las actividades, o el conocimiento de las ocupaciones del mundo laboral, que fueron dejados por la Terapia Ocupacional y tomados por la Salud Ocupacional. Al reconstruir la historia, en consecuencia, llama la atención la movilidad de la frontera de ese campo del conocimiento.

Si miramos nuestra pieza de tejido, hay elementos que estuvieron presentes en sus inicios, pero que en determinado período se han desvanecido. Por ejemplo, al comienzo de la historia de la Terapia Ocupacional en Colombia había más preocupación por la identidad, pues las hebras de la urdimbre se hicieron con las ciencias del comportamiento humano, con las de la salud, con las de la pedagogía, entre otras, y esa inquietud se convirtió en intranquilidad académica para profundizar, con otros profesionales, cómo se delimitaba la frontera de esta profesión al aceptar la incertidumbre y profundizar en la investigación. En la actualidad, a medida que se ha ampliado la frontera y se han delimitado sus elementos al interior, hay más profesionales trabajando en sus prácticas sin temores de identidad, pues las puestas en común han facilitado la delimitación del campo del conocimiento. De ahí que la dificultad de armar la historia se centra en que, cada vez más, los nuevos conocimientos son complejos de seguir, pues la amplitud del campo ha aumentado y la pieza de tejido se vuelve más elástica. 
Desde la responsabilidad de la academia, ella debe situarse en la frontera, porque la investigación que acepta la incertidumbre ayuda a delimitar el borde. El riesgo es que la academia sola quede de espaldas a la realidad por pensar en las utopías del conocimiento. Por ello, requiere de las experiencias y vivencias de los profesionales que ejercen las competencias disciplinares, para seguir tejiendo conjuntamente la pieza del campo de acción de la Terapia Ocupacional.

\section{¿Qué aporta la historia al devenir de la Terapia Ocupacional en Colombia?}

Este es el tiempo y el espacio de poner en común, de provocar otro tipo de lenguajes.

Remontarnos al revés en el tiempo es reconocer un punto de partida frágil, pues al estar despojados de los saberes establecidos, los períodos de la Terapia Ocupacional se han caracterizado por momentos de encuentros y desencuentros. Detenernos ahora para identificar qué fue lo que se hizo en esos momentos para avanzar hacia la pieza de tejido que tenemos hoy, es reconocer el peso fundamental que se le dio a la conversación de las acciones que cada quien realizaba.

Esas conversaciones se hicieron con lenguaje ético. El espacio para la conversación nos reunió, nos juntó y nos puso en común en un tiempo de aprendizaje, de sabernos ignorantes, de no tener tecnología, de incitar inquietudes y también de presentar contradicciones y provocar pensamientos no establecidos. Entonces, supimos va- lorar al Otro frente a la exposición de su argumento y pudimos conversar en desacuerdos y acuerdos. Prevaleció el sentido de la profesión de manera que se mantuvo el valor del lenguaje ético, más allá de los desarrollos personales, del discurso científicamente calificado y de los tecnicismos. Un lenguaje riguroso, con reglas sí, pero auténtico y que superó a cada una de las personas involucradas. Se fundamentó en una manera de ver las cosas, en gesto visual, es decir en una mirada, una óptica, una forma de mirar. Fueron modos de mirar limpiamente, con buenos ojos que determinaron en cada quien afectaciones positivas. Al mismo tiempo, también las conversaciones se llenaron de sonidos, fue cuando pudimos escuchar al Otro en la expresión de su idea, de su propia experiencia, de su historia singular, de su respuesta no universal. Fue empezar a construir un aprendizaje al diálogo, a la contención del Otro, lo que nos facilitó pertenecer a un colectivo en el que cada quien se sintió con cohesión, decisión y seguridad de aportar lo propio a la pieza de tejido de la Terapia Ocupacional.

El legado que dejamos a las nuevas generaciones de terapeutas ocupacionales consiste en una pieza de tejido en donde el aprendizaje tiene sentido como un espacio de Encuentro. El acto del Encuentro se refiere al espacio de descubrimiento con personas que tienen un nombre, un rostro, un lenguaje concreto; no conversamos en abstracto. El espacio de Encuentro tiene una doble función: i) estar disponible para el "Otro" que requiere el encuentro, pero también, ii) estarlo para entrar en relación "consigo mismo". 
En el Encuentro se pone en juego lo que llamamos "expresiones imperceptibles", sobre las que hay que trabajar muchísimo, porque hacen parte de las experiencias cotidianas, que parecen sencillas pero son profundas. Esas expresiones mínimas representan las formas de pensar, de hablar con las propias palabras acerca de las decisiones que se toman sobre las intervenciones con los sujetos, sobre las formas de ejecución de las actividades, sobre las interacciones, los materiales, herramientas y, sobre todo, de los procedimientos que se utilizan para el hacer.

Estar dispuesto para el Otro nos facilita la contradicción, pues provoca otro pensamiento, otro lenguaje, el que se opone al orden establecido. El Otro presenta su peso, su fuerza, su existencia en su pensamiento y sus códigos; nos expone sus propias historias, porque está hablando en nombre propio.

La relación consigo mismo exige detenimiento, descubrimiento y libertad. Es una búsqueda de dónde estamos a partir de la relación con el Otro; es comprenderse a partir de las diferencias y semejanzas con él. Es diferenciarse a partir de la evidencia del Otro, delimitado por el hálito de su palabra. Es comprenderse despojado de todo prejuicio de las intimidades retadoras del yo y de las normas sociales aceptadas. Es reconocerse en sus capacidades y retos.
La construcción de la pieza de tejido de la disciplina de la Terapia Ocupacional se realiza a través de aprendizajes, del despliegue de los mundos narrativos de las personas que viven momentos históricos complejos y de la consolidación de sus experiencias, que son reconocidos como un flujo continuo de percepción y discrepancia, de resistencia y de confrontación, en un colectivo que construye tramas de autonomía, reflexividad, articulación de sus acciones y que, por tanto, le da sentido a la pieza de tejido porque configura el espacio público del saber como un escenario de la realización política y la negociación del poder.

Dejamos unas preguntas instaladas para este momento histórico:

- ¿Qué significado tiene para las nuevas generaciones recapitular la historia de la Terapia Ocupacional?

- ¿La interpretación de los relatos del pasado resignifica nuestro quehacer actual y nos permite reubicarnos en el presente para reconocer cómo esos referentes adquieren un nuevo significado?

- ¿Significa un espectáculo en el que otros refieren vivencias que nos producen curiosidad? 